\title{
PENYIAPAN KEHIDUPAN BERKELUARGA BAGI REMAJA DI KOTA TASIKMALAYA
}

\section{PREPARATION OF FAMILY LIFE FOR YOUTH IN TASIKMALAYA CITY}

\author{
Peni Cahyati $^{1 *}$, Atit Tajmiati $^{2}$ \\ ${ }^{1}$ Departemen Keperawatan Politeknik Kesehatan Tasikmalaya \\ ${ }^{2}$ Departemen Kebidanan Politeknik Kesehatan Tasikmalaya \\ *Email: peni_poltekestsm@yahoo.com
}

(Diterima 30-12-2020; Disetujui 17-02-2021)

\begin{abstract}
ABSTRAK
Masa remaja merupakan masa transisi dari masa kanak-kanak ke masa dewasa. Secara fisik maupun kejiwaan banyak hal yang terjadi pada masa remaja. Periode ini sangat penting dipersiapkan agar remaja nantinya dapat tumbuh dan berkembang menjadi seorang dewasa yang sehat dan produktif. Masalah-masalah yang timbul pada masa remaja berbagai macam bentuknya karena remaja pada umumnya ingin mengetahui segala hal yang belum diketahuinya, dan ingin mencoba hal tersebut walupun tidak mengetahui efek negatif dari perbuatan tersebut. Untuk mewujudkan remaja yang mampu mengatasi masalah yang ada pada dirinya, serta mampu menghadapi tantangan ke depan yang akan semakin berat, maka pada diri remaja tersebut perlu ditanamkan kecakapan-kecakapan dalam hidup (life skills). Pendidikan life skills yang diterima oleh remaja dapat diperoleh oleh remaja tersebut secara sendiri melalui pengalaman dan aktivitas hidup, maupun melalui orang lain. Pendidikan life skills melalui perantara orang lain dapat melalui peranan Pusat Informasi Konseling Remaja (PIK-R). PIK-R dikembangkan melalui jalur pendidikan dan masyarakat, jalur pendidikan meliputi sekolah, perguruan dan pesantren. Sedang jalur masyarakat diantaranya melalui organisasi kepemudaan, organisasi keagamaan dan komunitas remaja.Kedua jalur tersebut merupakan sasaran yang penting untuk mendekati komunitas remaja. Pada saat ini PIK-R di Kota Tasikmalaya berjumlah 10 yang tersebar di 10 kecamatan, pembinaannya ada di bawah Dinas Pemberdayaan Perempuan, Perlindungan Anak, Pengendalian Penduduk dan Keluarga Berencana. Sebagai bentuk dukungan program ketahanan remaja untuk meningkatkan kualitas pengelolaan dan pelayanan PIK-R agar lebih maju dan mandiri dilaksanakan kegiatan pembekalan dengan tema "Peyiapan Kehidupan Berkeluaraga Bagi Remaja di Kota Tasikmlaya".
\end{abstract}

Kata Kunci: Pembinaan, kehidupan berkeluarga, remaja

\section{ABSTRACT}

Adolescence is a period of transition from childhood to adulthood. Physically and psychologically, many things happen during adolescence. This period is very important to prepare so that young people can grow and develop into healthy and productive adults. The problems that arise in adolescence take various forms because adolescents generally want to know everything they do not know, and want to try them even though they do not know the negative effects of these actions. In order to create adolescents who are able to overcome problems that exist within themselves, and are able to face the challenges ahead that will become increasingly severe, they need to be instilled in life skills. The life skills education received by adolescents can be obtained by them individually through life experiences and activities, as well as through other people. Life skills education through the intermediary of other people can be through the role of the Youth Counseling Information Center (PIK-R). PIK-R is developed through education and community channels, education channels include schools, colleges and Islamic boarding schools. Meanwhile, the community channels include youth organizations, religious organizations and youth communities. Both channels are important targets for approaching the youth community. Currently, there are 10 PIK-Rs in Tasikmalaya City spread over 10 sub-districts, their guidance is under the Office of Women's Empowerment, Child Protection, Population Control and Family Planning. As a form of support for the youth resilience program to improve the quality of PIK-R management and services so that it is more advanced and independent, a debriefing activity was carried out with the theme "Preparation of Sustainable Life for Youth in the City of Tasikmlaya".

Keywords: coaching, family life, youth 
Penyiapan Kehidupan Berkeluarga Bagi Remaja di Kota Tasikmalaya

Peni Cahyati, Atit Tajmiati

\section{PENDAHULUAN}

Masa remaja adalah masa mencari identitas diri. Remaja lebih senang menghabiskan waktu bersama dengan ternan-ternan sebaya. Pola perilaku pada remaja pun lebih sering dipengaruhi oleh teman-teman sebaya. Jika remaja masuk dalam kelompok remaja yang berperilaku baik, maka remaja tersebut cenderung berperilaku baik pula. Jika remaja masuk dalam kelompok anak yang berperilaku kurang baik, maka remaja tersebut cenderung berperilaku seperti teman-teman yang ada di kelompoknya, yaitu berperilaku kurang baik. Beberapa contoh perilaku remaja yang kurang baik adalah pemakaian obatobatan terlarang dan alkohol, kenakalan remaja, kehamilan remaja, bunuh diri, dan gangguan-gangguan makan karena merasa tidak puas dengan bentuk tubuhnya (Santrock, 2002).

Menurut Hartini (1999), cukup banyak remaja yang jatuh dalam narkoba, pergaulan bebas, dan masalah-masalah sosial lainnya. Hartini juga menjelaskan bahwa masa remaja adalah masa dimana mereka ingin mendapatkan pengakuan dari orang-orang di sekitamya, atau lebih tepatnya yaitu masa untuk mencari identitas diri. Masa remaja, khususnya remaja awal, adalah masa-masa mencari identitas diri karena pada masa ini lah, remaja mulai mencari identitas yang tepat untuk dirinya dengan mengikuti ternan sebaya, namun masih tetap bisa diatur oleh norma yang berlaku.

Permasalahan remaja pada saat ini merupakan hal kompleks dan semakin menjalar dan sering terjadi di lingkungan masyarakat sekitar. Selain karena jumlah remaja mencapai $27.6 \%$ dari total penduduk Indonesia, atau sekitar 64 juta jiwa. Fakta menunjukkan sebagian remaja kini dihadapkan pada situasi yang sangat memprihatinkan seperti seks pranikah, narkoba, dan lainnya. Selain itu, juga tingkat pernikahan dini masih tergolong tinggi. Pernikahan dini sendiri menempatkan remaja putri dalam resiko tinggi terhadap kehamilan dini dan kehamilan tidak diinginkan, dengan konsekuensi ancaman kehidupan. Bila tren ini terus berlanjut, 142 juta remaja putri akan melakukan pernikahan sebelum mereka berusia 18 tahun sebelum 2020. Hal ini berarti 14,2 juta remaja putri melakukan pernikahan setiap tahun atau 39 ribu setiap hari. Pencegahan pernikahan dini akan membantu penurunan risiko infeksi pada saat melahirkan bahkan 'ancaman' kematian pada saat ibu melahirkan serta bayi cacat lahir.

Menururt Wardoyo (2019), bahwa remaja merupakan individu calon pasangan yang akan membangun keluarga dan calon orang tua bagi anak-anak yang dilahirkannya agar memiliki perencanaan dan kesiapan berkeluarga/penduduk usia produktif yang harus disiapkan. Kesiapan berkeluarga merupakan salah satu kunci terbangunnya ketahanan 
keluarga dan keluarga yang berkualitas sehingga diharapkan mampu melahirkan generasi yang juga berkualitas. Penanggulangan kenakalan remaja merupakan tanggung jawab berbagai pihak, yakni pada remaja itu sendiri, orang tua dan seluruh komponen masyarakat bersama pemerintah. Menurut Sukirno (2019), jalan untuk mengatasi kenakalan remaja adalah dibangunnya kesadaran bersama bahwa tanggung jawab mendidik dan membimbing remaja berada pada remaja itu sendiri, orang tua, masyarakat dan pemerintah, jadi tidak pada remaja itu sendiri. Pemerintah mengharapkan adanya kerjasama berbagai pihak untuk mendapatkan hasil yang maksimal dalam upaya pencegahan kenakalan remaja. Para remaja diharapkan menempa diri menjadi pemudapemuda yang memiliki akhlak yang mulia, berdisiplin tinggi, bermoral, kerja keras, jujur, kreatif dan inovatif dan bermental tangguh menghadapi tantangan jaman.

Sosiolog Robertus Robert menilai bahwa penanganan kenakalan remaja harus mendapatkan perhatian dari pemerintah. Sebab, peran orang tua saja tidak bisa untuk membuka simpul masalah kenakalan remaja. Dalam rangka merespon permasalahan remaja tersebut, maka pemerintah melalui Dinas Pemberdayaan Perempuan, Perlindungan Anak, Pengendalian Penduduk dan Keluarga Berencana sesuai dengan amanat UU No.52 Tahun 2009 mengembangkan program yaitu Program Generasi Berencana yang disingkat menjadi GenRe. Program GenRe adalah program yang dikembangkan dalam rangka penyiapan kehidupan berkeluarga bagi remaja sehingga mereka mampu melangsungkan jenjang pendidikan secara terencana, berkarir dalam pekerjaan secara terencana, serta menikah dengan penuh perencanaan sesuai siklus kesehatan reproduksi. Program GenRe ditujukan kepada remaja/mahasiswa melalui wadah Pusat Informasi dan Konseling Remaja (PIK-R) dan keluarga yang memiliki remaja melalui wadah Bina Keluarga Remaja (BKR). Untuk meningkatkan kualitas pengelolaan dan pelayanan PIK-R perlu dikembangkan suatu kegiatan yang memacu kelompok-kelompok tersebut untuk meingkatkan kualitas dan kapasitasnya melalui program seminar, pelatihan, studi banding dan lain-lain.

\section{BAHAN DAN METODE}

Kegiatan penyuluhan dilaksanakan pada hari Kamis, tanggal 19 Desember 2020 di Aula Kantor Dinas Pengendalian Penduduk Pemberdayaan Perempuan dan Perlindungan Anak Kota Tasikmlaya. Diikuti oleh 45 orang peserta dari pengurus PIK-R Kota Tasikmalaya yang tersebar di 10 kecamatan. Metode yang digunakan dalam kegiatan pengabdian kepada masyarakat ini adalah dengan metode ceramah, penayangan video kesehatan reproduksi, dan diskusi. Evaluasi tingkat keberhasilan kegiatan ini dilakukan 
Penyiapan Kehidupan Berkeluarga Bagi Remaja di Kota Tasikmalaya

Peni Cahyati, Atit Tajmiati

melalui pre test, quis dan post test tentang pengetahuan Kesehatan Reproduksi dan Persiapan Pra Nikah.

\section{HASIL DAN PEMBAHASAN}

Bentuk partisipasi perserta pelatihan ini cukup aktif dan menyambut baik program pembekalan bagi anggota PIK-R se Kota Tasikmalaya tentang Kehidupan Berkeluarga Bagi Remaja. Kegiatan penyuluhan dilaksanakan pada hari Kamis, tanggal 19 Desember 2020 di Aula Kantor Dinas Pengendalian Penduduk Pemberdayaan Perempuan dan Perlindungan Anak Kota Tasikmlaya. Diikuti oleh 40 orang peserta dari pengurus PIK-R Kota Tasikmalaya yang tersebar di 10 kecamatan (Gambar 1 dan 2).

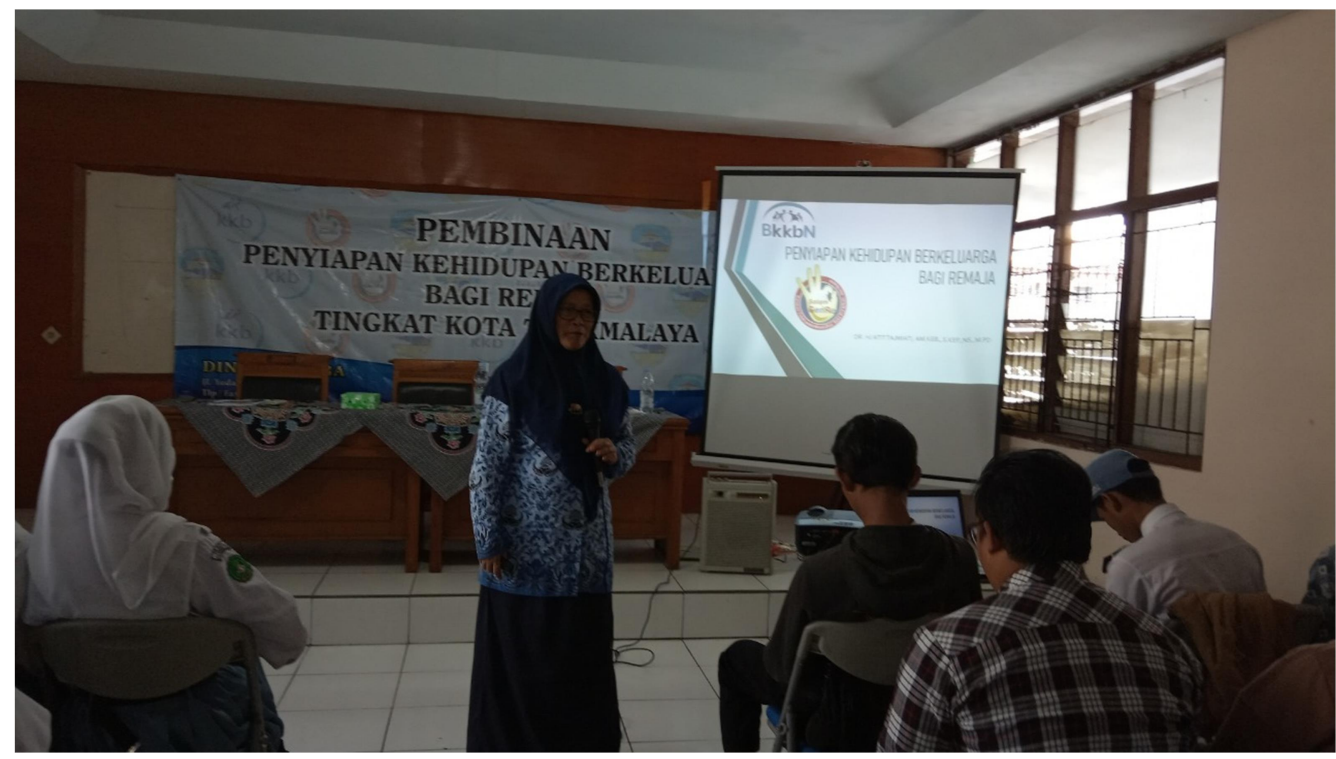

Gambar 1. Kegiatan Penyuluhan

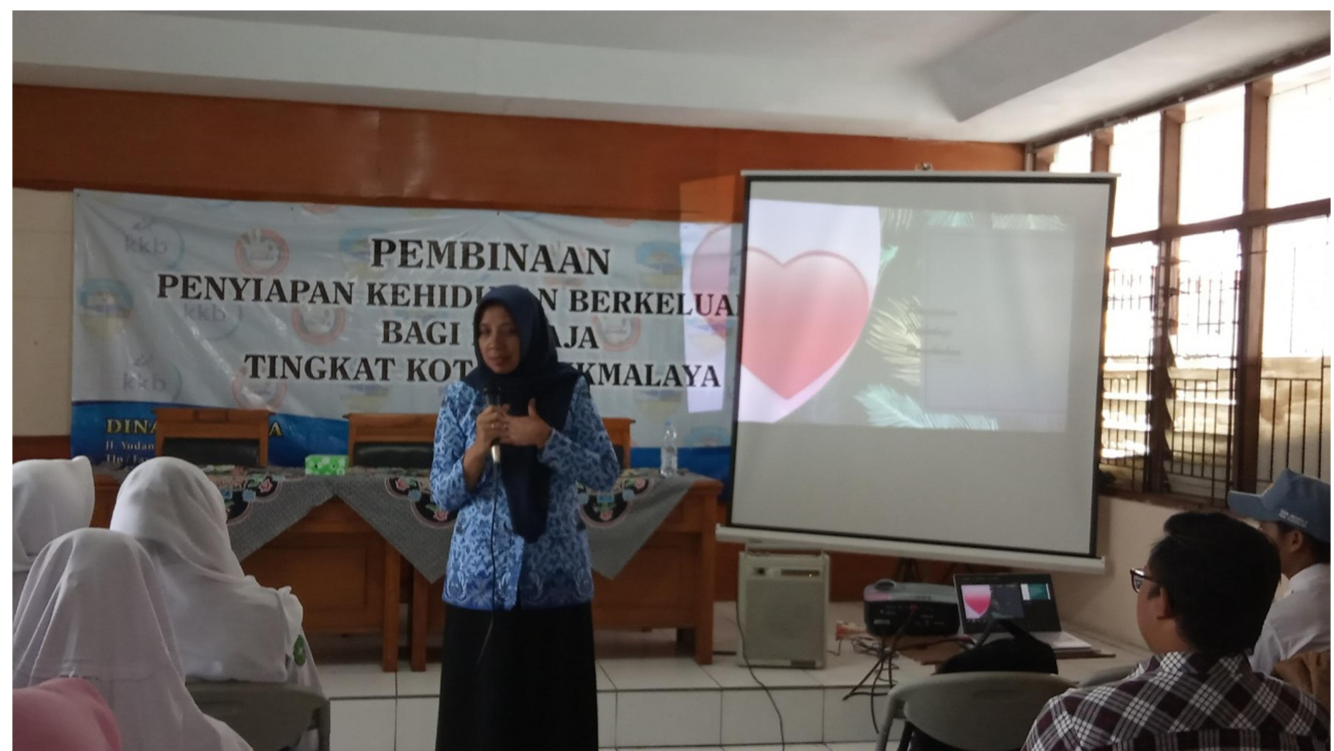

Gambar 2. Kegiatan Penyuluhan 
Kegiatan pengabdian kepada masyarakat yang dilaksanakan dengan cara tatap muka berjalan dengan baik dan lancar. Untuk mengetahui keberhasilan kegiatan ini dilaksanakan pre test dan post test dengan memberikan soal yang sama dengan bentuk pilihan ganda sebanyak 15 soal sehingga di ketahui tingkat pemahaman dari masing-masing perserta. Berdasarkan hasil penilaian pre test, didapatkan nilai rata-rata peserta 52, dan hasil penilaian post test didapatkan nilai rata-rata peserta 86. Dengan demikian, ada peningkatan nilai dari pre test ke post test artinya perseta pelatihan pengetahuannya meningkat secara signifikan.

\section{KESIMPULAN DAN SARAN}

Pelaksanaan kegiatan pengabdian kepada masyarakat ini berjalan dengan baik dan lancar sesuai dengan rencana yang telah disusun. Secara umum seluruh perserta dapat menjelaskan tentang kesehatan reproduksi dan persiapan pra nikah. Berdasarkan evaluasi yang dilakukan adanya peningkatan pengetahuan tentang kesehatan reproduksi dan persiapan pra nikah. Program PIK-R harus terus dibina dan dikembangkan lebih baik lagi dengan kegiatan yang menarik agar para remaja tertarik untuk bergabung dan menjadi anggota.

\section{DAFTAR PUSTAKA}

Badan Kependudukan dan Keluarga Berencana Nasional. (2012). Pedoman Pengelolaan Pusat Informasi dan Konseling Remaja dan Mahasiswa (PIK-R/M), Direktorat Bina Ketahanan Remaja. Jakarta. . (2009). Pedoman Pengendalian Pusat Informasi dan Konseling Remaja (PIKRemaja), Direktorat Remaja dan Perlindungan Hak-hak Reproduksi. Jakarta.

Pataki, C.S. (2006), Adolescent Development, in Kaplan \& Sadock's Comprehensive Textbook of Psychiatry, 9th Editio., B. J. Sadock, V. A. Sadock, and P. Ruiz, Eds. philadelphia: Lippincott Williams \& Wilkins.

Hatini, N. (1999). Remaja dan Lingkungan Sosialnya. Jumal Anima, 1(15): 76-82. https//warta jogja. Go.id/detail/index/2296 di unduh tanggal 24 Desember 2020. https//www.med.com.id/nasional/peristiwa/ibVEMBN-sosiolog-kenakalan remaja-perluperhatian-pemerintah. Diunduh tanggal 24 Desember 2020.

Santrock, J. (2002). Adolescence, perkembangan remaja, edisi keenam. Jakarta: Erlangga. Undang-undang No. 52 Tahun 2009 tentang Perkembangan Kependudukan dan Pembangunan Keluarga. 